\title{
Health-care services utilization and costs associated with radical cystectomy for bladder cancer: a descriptive population-based study in the province of Quebec, Canada
}

\author{
Fabiano Santos ${ }^{1}$, Alice Dragomir ${ }^{2}$, Ahmed Sayed Zakaria², Wassim Kassouf ${ }^{2}$ and Armen Aprikian²*
}

\begin{abstract}
Background: Bladder cancer (BC) has the highest lifetime treatment costs per patient of all cancers. The objective of this study was to characterize the use of health-care services and costs associated with BC among patients who underwent radical cystectomy (RC) in the province of Quebec.

Methods: We conducted a descriptive study in a retrospective cohort of patients who underwent RC for BC between 2000 and 2009. Data was obtained from two health administrative databases (RAMQ and ISQ). We calculated average costs per patient and total costs in 2014 Canadian dollars for the following components of costs: 1) Pre-surgery costs (pre and post-urologist consultations, urologist consultations, cystoscopies, TURBTs, imaging procedures); 2) Costs of radical cystectomy and 3) Post-surgery costs (urologist consultations, post-operative consultations, medical oncologist consultations, imaging procedures and post-operative complication management). ARIMA models were used to evaluate trends in average costs per patient over the study period.

Results: Among 2759 patients included in the study (75\% men), average pre-surgery costs, RC costs, and post-surgery costs were estimated at $3762 \$, 18979 \$$ and $4770 \$$, respectively. RC cost was responsible for $69 \%$ of total costs, followed by post-operative consultations (7.8\%), post-operative complications and TURBTs ( $6 \%$ of total costs, each). Academic hospitals performed RC at a lower average cost, compared to community hospitals (difference of $\$ 1000, p<.0001$ ). A decreased trend in post-surgery costs was detected in the year 2009.

Conclusions: Costs of RC, TURBT, consultations and post-operative complications were the most important economic components of total RC cost per patient in Quebec. Academic hospitals performed RC at a lower cost, compared to community hospitals.
\end{abstract}

Keywords: Bladder cancer, Radical cystectomy, Health-services utilization, Costs

\section{Background}

Bladder cancer (BC) has the highest lifetime treatment costs per patient of all cancers, from diagnosis to death $[1,2]$. Perioperative and post-operative complications, high recurrence rates, intensive surveillance strategies, and expensive treatment costs are the key contributors to the economic and health-services burden of this disease [3]. $\mathrm{BC}$ is the second most prevalent urological

\footnotetext{
* Correspondence: armen.aprikian@muhc.mcgill.ca

${ }^{2}$ Division of Urology, Department of Urology, McGill University Health Centre, 1650 Cedar Avenue, Montreal, QC, Canada

Full list of author information is available at the end of the article
}

cancer worldwide and the fifth most common diagnosed malignancy in Canada, with 8000 incident cases and 2200 deaths expected for 2014 [4]. In the USA, 74 690 new cases and 15580 deaths from BC are estimated for this year [5]. A quarter of patients present with muscle invasive $\mathrm{BC}$, and about half of these individuals have occult distant metastases at the time of presentation [3]. Transurethral resection of the bladder tumor (TURBT) is a diagnostic and therapeutic intervention in cases of superficial disease, while muscle invasive bladder cancer often requires radical cystectomy (RC) [6]. Epidemiologic trends, aging and evolving 
population demographics along with technological advances in endoscopy, diagnostic and surgical technique will make the management of patients with bladder cancer in the near future a more substantial economic challenge $[7,8]$. There is a lack of studies on the trajectories of $\mathrm{BC}$ patients in the continuum of care with respect to costs and the use of medical services [8]. Therefore, the objective of the present study was to describe health-care utilization and associated costs among patients who underwent $\mathrm{RC}$ for $\mathrm{BC}$ in the province of Quebec - Canada, as from the public healthcare system perspective.

\section{Methods}

\section{Study design}

We conducted a descriptive study analyzing health-care services utilization and costs associated with $\mathrm{BC}$ in a retrospective cohort of patients who underwent radical cystectomy in Quebec between the years 2000 and 2009.

\section{Data source}

The cohort was built with the linkage of two provincial health administrative databases: the medical billing records database of the Régie de l'assurance maladie $d u$ Québec (RAMQ), and the Fichier des évenements démographiques de l'Institut de la statistique du Québec (ISQ). The RAMQ is the government body that administers healthcare provision in the province. All healthcare services are recorded in the RAMQ administrative databases and its associated claims files. The RAMQ claim file provides information on medical services dispensed to all Quebec residents (information on physician-based ICD-9 diagnostic codes, act codes for therapeutic procedures, their calendar dates and associated costs, characteristics of the patient, health care providers and hospital facilities). The ISQ administers the Fichier des événements démographiques which provides vital status data. The linkage between RAMQ and ISQ data is possible using a patients' anonymous identifier (generated from the Numéro d'assurance maladie - NAM, which is a unique identifier for all legal residents of Quebec). The use of the data was approved by the Comission de l'acces a l'information (CAI) of Quebec. Ethics approval was obtained from the Research Ethics Board of the McGill University Health Centre.

\section{Study population}

Patients were selected from January 1st 2000 to September 30th 2009. We excluded subjects aged less than 40 years-old (the age cut-off point for micro-hematuria workup in Canada) [9]. The index date is the date on which each patient entered into the cohort (calendar date of RC).

\section{Health-care services utilization}

We identified health-care services utilization for patients who underwent $\mathrm{RC}$ for $\mathrm{BC}$ cancer during the 4 months period before RC. The 4 months' time frame was adopted to assure that all medical services consumed by patients were associated to $\mathrm{RC}$ for $\mathrm{BC}$. We identified the following components of health-care utilization: 1) Pre-surgery period (pre-and posturologist consultations, urologist consultations, cystoscopies, TURBTs, pathology and imaging procedures), 2) Surgical period (RC), and 3) Post-surgery period (postoperative urologist, medical oncologist, and other consultations, and imaging procedures). Post-surgery health services were determined up to one year after surgery.

\section{Cost assignments}

Analogously to the time frame adopted for the identification of health-care services, we calculated average costs per patient and total costs for the following components of costs on the continuum of care for BC : 1) Pre-surgery costs (cost of pre-urologist consultations, cost of post-urologist consultations, cost of urologist consultations, costs of cystoscopies, costs of TURBTs, costs of pathologic and imaging procedures; 2) Costs of $\mathrm{RC}$, and 3) Post-surgery costs (costs of urologist consultations, costs of post-operative consultations, costs of medical oncologist consultations, costs of imaging procedures and costs of post-operative complications management). The unit cost of each medical service for consultations and imaging procedures was documented from the RAMQ's list of medical procedures act codes approved for physician reimbursement fees in Quebec $[10,11]$. We did not include costs associated to equipment and maintenance when computing costs for imaging procedures. When applicable, average and total costs for cystoscopy, TURBT and RC included estimation of hospitalization costs, pathology reports, urine cytology, anesthetist fees and surgical cardio-pulmonary monitoring. We assumed that each cystoscopy generates one urine cytology report; each TURBT leads to a same-day hospitalization stay and 1 pathology report, and each RC leads to 7 days hospitalization and 1 pathology report. Post-operative complications were identified by means of RAMQ procedure flash act codes, as described in previous work [12]. Hospitalization and pathology costs were estimated from the Ministere de la Sante et des Services Sociaux (MSSS) du Quebec and the McGill University Health Centre administration, respectively $[13,14]$. The unit costs and sources are presented in Table 1. All costs were assigned in Canadian dollars and were estimated from the 2014 Quebec's public healthcare system perspective. 
Table 1 Costs associated with bladder cancer: Cost Components and Unit cost. Time horizon: from 4 months prior to radical cystectomy until 1 year after surgery ${ }^{a}$

\begin{tabular}{lll}
\hline Procedure & Unit cost $^{\mathrm{b}}$ & Source \\
\hline PRE-SURGERY & & \\
Pre-urologist consultations & Bladder cancer cohort \\
- Physician fees & $\$ 50$ & \\
& Range: $\$ 15.20-\$ 94.4$ &
\end{tabular}

Post-urologist consultations

- Physician fees

$\$ 50$

Bladder cancer cohort

Range: $\$ 15.20$ - \$94.4

Urologist consultations

- Physician fees

$\$ 40$

Range: $\$ 16.9-45.6$

Cystoscopies

- Physician fees

$\$ 50.9$

- Procedure fees

$\$ 192.3$

- Urinary cytology

$\$ 87$

TURBT

- Physician fees \$208

- Hospitalization $\quad \$ 1371$

- Anesthesia physician $\$ 150$

fees

- Pathology report $\$ 40$

Imaging

- Physician fees

$\$ 45$

Range: \$16.5 - \$200

RADICAL

CYSTECTOMY

$\begin{array}{ll}\text { - Physician fees } & \$ 1880 \\ \text { - Hospitalization } & \$ 14855 \\ \text { - Anesthesia physician } & \$ 1160 \\ \text { fees } & \\ \text { - Pathology report } & \$ 450 \\ \text { POST-SURGERY } & \end{array}$

RAMQ reimbursement act code list $(10,11)$

Quebec MSSS (14)

RAMQ reimbursement act code list $(10,11)$

MUHC administration

Post-operative consultations

- Physician fees

$\$ 50$

Range: \$ 15.20 - \$94.4

Post-operative urologist

consultations

- Physician fees

$\$ 40$

Bladder cancer cohort

Range: $\$ 16.9$ - 45.6

Post-operative medical oncologist consultations

- Physician fees
Table 1 Costs associated with bladder cancer: Cost Components and Unit cost. Time horizon: from 4 months prior to radical cystectomy until 1 year after surgery ${ }^{a}$ (Continued)

\begin{tabular}{|c|c|c|}
\hline & Range: $\$ 16.9-\$ 98$ & \\
\hline \multicolumn{3}{|c|}{ Post-operative imaging } \\
\hline \multirow[t]{2}{*}{ - Physician fees } & $\$ 45$ & Bladder cancer cohort \\
\hline & Range: \$ 16.5 - \$200 & \\
\hline \multicolumn{3}{|l|}{$\begin{array}{l}\text { Post-operative } \\
\text { complications }\end{array}$} \\
\hline \multirow[t]{2}{*}{ - Physician fees } & $\$ 550$ & Bladder cancer cohort \\
\hline & Range: $\$ 61.5-\$ 1184$ & \\
\hline - Hospitalization & $\$ 1371$ & Quebec MSSS (14) \\
\hline
\end{tabular}

\section{Covariates}

We analysed $\mathrm{BC}$-associated costs across two groups of variables: 1) Patient-related variables: age (four categories: less than 60, 60-69, 70-75, more than 75 years) and gender (dichotomous); and 2) Health-care services related variables: hospital facility where RC was performed, hospitals hosting an urology teaching program (dichotomous), surgeons' annual RC case load (three categories: surgeons who perform less than $3 \mathrm{RC} /$ year, surgeons who perform between 3-9 RC per year and surgeons who perform more than $9 \mathrm{RC} /$ year), geo-administrative region where $\mathrm{RC}$ was performed (4 regions, grouped A to D) and calendar date of RC. Geo-administrative division is based on the MSSS's Academic Integrated Network of Health which divides the province of Quebec into four regions according to provision of medical services and university affiliation [15].

\section{Statistical analyses}

Demographic characteristics, age and gender-specific information of the study population was retrieved. Descriptive statistical analyses, including mean, median, standard deviation (SD) and range of costs were calculated, along with patient's units of medical services related to each component of costs. Normality of data distribution was analysed by the Shapiro-Wilk test. Comparisons of average costs between groups were performed by t-tests and ANOVA tests, when applicable. We used autoregressive integrated moving average (ARIMA) models to evaluate trends in average total costs per patient, average radical cystectomy costs per patient and post-surgery costs per patient. We analysed differences between observed and forecasted average costs per patient over 117-month periods ranging from January 2000 to September 2009. Cut-off points for comparison between observed and forecasted values were established after seasonal trends inspection of the time series plot for 
each component of cost. Stationarity was assessed using the autocorrelation function and the augmented Dickey Fuller test. The autocorrelation, partial autocorrelation, and inverse autocorrelation graphic functions were used to model parameter appropriateness and seasonality. The presence of white noise was assessed by examining the autocorrelation at various lags using the Lung-Box chi squared test. All analyses were two-sided with $\mathrm{p} \leq 0.05$ being considered significant. SAS 9.3 (SAS Institute Inc., Cary, NC, USA) was used to conduct the calculations.

\section{Results}

\section{Characteristics of the study cohort and the health-care system}

Baseline characteristics of the cohort are summarized in Table 2. We analyzed a cohort formed by 2759 patients who underwent RC for BC and with medical services data available for the four months period before RC (75\% were men). Approximately $30 \%$ of patients had post-operative complications. A total of 1355 patients (49 \%) died during the study time period. Mean and median follow-up of the cohort was 34 months (standard deviation: 32 months) and 21.6 months (range: 1 day-118 months), respectively. The estimated overall 5-year survival rate was $46 \%$. During the study period, RCs were performed by 122 surgeons in 42 hospitals across the province. A total of $42 \%$ of surgeries were performed in a hospital hosting a urology training program, whereas $43 \%$ of procedures were performed in hospitals with an annual case load of $<10$ RCs per year. Surgeons with an annual RC case load of $<3$ RCs per year were responsible for $58 \%$ of RCs.

Health care services utilization and costs associated with bladder cancer: pre and post-RC operative period

Average costs per patient and mean units of medical services for each component are summarized in Table 3. Figure 1, Fig. 2(a) and (b) illustrate the weighted average of cost components for the pre and post-operative periods, and costs according to patient's gender and age, respectively. Patients had a mean of 4.7 consultations with other specialists before their first urologist visit (average costs of pre-urologist consultations per patient: 1006 \$). Mean number of urologist consultations and TURBTs in the four months before $\mathrm{RC}$ was 4.7 and 1.2 respectively. The average cost of TURBT was the most significant component of costs during the pre-operative period (2159\$), representing $40 \%$ of total average costs before surgery. Patients tended to have more expensive post-operative urologist consultations compared to the pre-operative period (average cost of $437 \$$ per patient in the post-operative period compared to $162 \$$ in the pre-operative period). Imaging procedures were also used more frequently and at a higher cost after surgery (4.5 post-operative imaging procedures per patient
Table $\mathbf{2}$ Characteristics of the study population

\begin{tabular}{|c|c|}
\hline & Total $(2759,100 \%)$ \\
\hline \multicolumn{2}{|l|}{ Patient-related variables } \\
\hline \multicolumn{2}{|l|}{ Gender } \\
\hline Male & $2091(75.8 \%)$ \\
\hline Female & $668(24.2 \%)$ \\
\hline \multicolumn{2}{|l|}{ Age } \\
\hline Less than 60 years-old & $643(23.3 \%)$ \\
\hline Between 60-69 years-old & $828(30 \%)$ \\
\hline Between $70-75$ years-old & $557(20.2 \%)$ \\
\hline More than 75 years-old & $731(26.5 \%)$ \\
\hline \multicolumn{2}{|l|}{ Post-operative complications } \\
\hline Yes & $849(30.7 \%)$ \\
\hline No & $1910(69.3 \%)$ \\
\hline Overall mortality & 1355 (49.1 \%) \\
\hline 5 years overall survival & $46 \%$ \\
\hline \multicolumn{2}{|l|}{ Health system characteristics } \\
\hline \multicolumn{2}{|c|}{ RUIS-MSSS region where surgery was performed } \\
\hline Region A & $1342(48.6 \%)$ \\
\hline Region B & $632(23 \%)$ \\
\hline Region C & $563(20.4 \%)$ \\
\hline Region D & $222(8 \%)$ \\
\hline Surgery in a urology teaching hospital & $1172(42.48 \%)$ \\
\hline \multicolumn{2}{|l|}{ Hospital annual RC case load } \\
\hline Less than $10 \mathrm{RCs}$ per year & $1184(42.9 \%)$ \\
\hline Between 10-25 RCs per year & $934(33.8 \%)$ \\
\hline More than 25 RCs per year & $641(23.3 \%)$ \\
\hline \multicolumn{2}{|l|}{ Surgeon annual RC case load } \\
\hline Less than 3 RCs per year & $1621(58.7 \%)$ \\
\hline Between 3-9 RCs per year & $814(29.6 \%)$ \\
\hline More than 9 RCs per year & $324(11.7 \%)$ \\
\hline
\end{tabular}

with an average cost of 395 \$). No significant differences were observed for these components of costs according to gender (Fig. 2(a)). On the other hand, older patients tended to have higher pre and post-operative costs (Fig. 2(b)).

\section{Cost of radical cystectomy}

Cost of RC is shown in Table 3, and graphically illustrated in Figs. 3((a) and (b)). Average cost of surgery per patient was estimated at 18979 \$. Surgery was 207 \$ more expensive in men compared to women (Fig. 2(a), $\mathrm{p}<.0001$ ), and more costly in older patients (19 $032 \$$ Fig. 2(b), $\mathrm{p}=0.0002$ ). Region A was the only administrative region with hospitals performing $\mathrm{RC}$ at a cost higher than the average (19 329 \$, Fig. 3(a), p <.0001). Hospitals hosting a urology training program performed $\mathrm{RC}$ at an average of 1000 \$ less expensive (at $5 \%$ ), compared to community hospitals (Fig. 3(b), p <.0001). 
Table 3 Average costs per patient attributable to the health continuum of care for bladder cancer. (Time window: from four months before radical cystectomy up to 1 year post surgery. Costs shown in Canadian dollars)

\begin{tabular}{|c|c|c|c|c|c|}
\hline & N (\%) & $\begin{array}{l}\text { Mean and standard deviation } \\
\text { (SD) of service units per patient }\end{array}$ & $\begin{array}{l}\text { Median (IQR) service } \\
\text { units per patient }\end{array}$ & $\begin{array}{l}\text { Mean and standard deviation (SD) of } \\
\text { costs per patient (Canadian dollars) }\end{array}$ & $\begin{array}{l}\text { Median and range of costs } \\
\text { per patient (Canadian dollars) }\end{array}$ \\
\hline \multicolumn{6}{|l|}{ PRE-SURGERY COSTS $(n=2759)$} \\
\hline $\begin{array}{l}\text { Pre-urologist consultations } \\
\text { (all specialties confounded, } \\
\text { excluding urologists) }\end{array}$ & $2332(84.5 \%)$ & Mean: 4.7 (SD: 5.17) & Median: 3 (IQR: 2-6) & Mean: 1006 (1299) & Median: 450 (10-7834) \\
\hline $\begin{array}{l}\text { Post-urologist consultations } \\
\text { (all specialties confounded, } \\
\text { excluding urologists) }\end{array}$ & 2155 (78.1\%) & Mean: 4.3 (SD: 4.2) & Median: 3 (IQR:2-5) & Mean: 935 (1038) & Median: 523 (6.2-6000) \\
\hline Urologist consultations & 2731 (99 \%) & Mean: 4.7 (SD: 3.8) & Median: 4 (IQR:3-6) & Mean: $162(80)$ & Median: 140 (17-1959) \\
\hline Cystoscopies & $1896(68.7 \%)$ & Mean: 1.19 (SD: 0.46) & Median: 1 (IQR: 1-1) & Mean: 323 (37) & Median: 273 (273-870) \\
\hline TURBTs & $2058(74.6 \%)$ & Mean: 1.15 (SD: 0.39) & Median: 1 (IQR:1-1) & Mean: 2159 (773) & Median: 1911 (1703-4115) \\
\hline Imaging (physician fees) & 2532 (91.7 \%) & Mean: 2.5 (SD: 1.55) & Median: 2 (IQR: 1-3) & Mean: 242 (154) & Median: 205 (12-1397 \\
\hline \multicolumn{6}{|l|}{ RADICAL CYSTECTOMY COSTS } \\
\hline Radical cystectomy & $2759(100 \%)$ & 1 & 1 & Mean: 18979 (1168) & Median: 18440 (16 005-25 684) \\
\hline \multicolumn{6}{|l|}{ POST-SURGERY COSTS } \\
\hline Post-operative urologist consultations & $2606(94.5 \%)$ & Mean: 4.7 (SD: 5.17) & Median: 3 (IQR: 2-6) & Mean: 437 (635) & Median: 196 (17-9479) \\
\hline $\begin{array}{l}\text { Post-operative consultations } \\
\text { (all specialties confounded, excluding } \\
\text { urologists and medical oncologists) }\end{array}$ & $2742(99.4 \%)$ & Mean: 32 (SD: 29) & Median: 24 (IQR: 13-41) & Mean: 2232 (2275) & Median: 1464 (17-27057) \\
\hline Post-operative medical oncologist consultations & $809(29.3 \%)$ & Mean: 10 (SD: 10.9) & Median: 7 (IQR: 2-14) & Mean: 526 (579) & Median: 346 (14.75-3860) \\
\hline Post-operative imaging (physician fees) & $2535(92.1 \%)$ & Mean: 4.5 (SD: 3.3) & Median: 4 (IQR: 2-6) & Mean: 395 (307) & Median: 311 (12.3-2845) \\
\hline Post-operative complications & $811(29.4 \%)$ & Mean: 3.7 (SD: 3.36) & Median: 3 (IQR: 2-5) & Mean: 5703 (2076) & Median: 5062 (4017-18878) \\
\hline
\end{tabular}




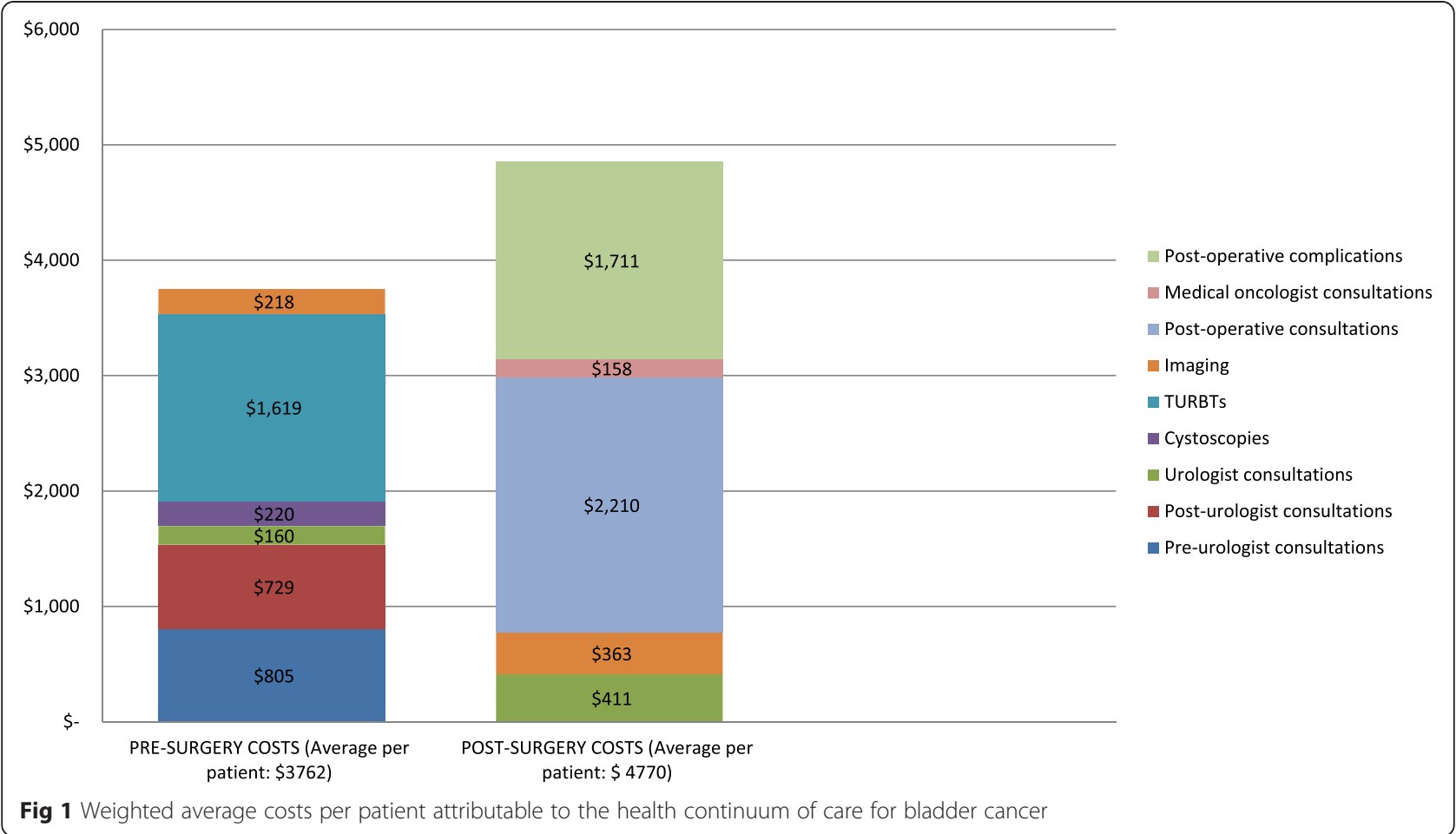

\section{Cost of post-operative complications}

Cost of post-operative complications is shown in Table 3, and graphically illustrated in Fig. 1, Fig. (4(a) and (b)). Average cost of post-operative complications was the most significant component of costs after surgery. Among patients who had these complications (30\%); patients had a mean of 3.7 complications at an average cost of 5703 \$ per patient. An extreme variation in the average costs per patient was identified among hospitals across the province, with hospitals of the Region $\mathrm{D}$ having the higher average costs per patient (6015 \$, compared to $5782 \$$ in region $A, 5530 \$$ in region $B$ and $5610 \$$ in region $C$ ). Hospitals hosting a urology teaching program showed a non-significant lower average costs per patient for postoperative complications, compared to community hospitals (5582 $\$$ and $5811 \$$, respectively).

\section{Total costs of bladder cancer}

Units of health services utilization and its total costs are described in Table 4. Table 5 displays average and total RC costs per patient, average and total pre-surgery cost per patient and average and total post-surgery costs per patient stratified by year. Percentages of each component of costs are graphically represented in Fig. 5. Over 10 years, total costs of $\mathrm{BC}$ requiring radical cystectomy to the provincial health system was estimated at 75563893 \$. During the study period, $2759 \mathrm{RCs}$ were performed at a cost of 52372057 \$, representing $69 \%$ of total costs of RC for $\mathrm{BC}$ (Fig. 5). Post-operative consultations was the second most expensive component (5 594 774 \$. $7 \%$ of total costs) followed by post-operative complications (4 356 $127 \$, 6 \%$ of BC total costs) and TURBTs (4 340247 \$, $6 \%$ of total costs).

\section{Time series and trend analyses}

Figure 6 demonstrates time trends in average RC costs per patient (A), average post-operative costs per patient (B) and average total costs per patient (C) over the 117 month period between January 2000 and September 2009. Trends in average $\mathrm{RC}$ costs per month were described by an ARIMA $(2,1,1)$ model, with comparison between observed and forecasted values modeled from period 72 (January 2006), and forecasted up to period 117. Period 72 was chosen as a cut-off point because of an apparent decreasing trend for this component of cost starting from this period, as inspected at the time series plot for this component of cost. No significant trend was detected over time (Fig. 6(a)). On the other hand, we observed a non-significant decreased trend during the year 2009 for the average of post-operative and total costs per month, as described by two independent ARIMA $(1,1,0)$ models (Fig. 6(b) and (c)). A significant difference of -5175 \$ was detected between observed and predicted values of average post-operative costs in September 2009. In addition, a significant difference of $-6000 \$$ was detected between observed and predicted average total costs in September 2009. These decreases in costs are attributed to a lower average cost of medical 


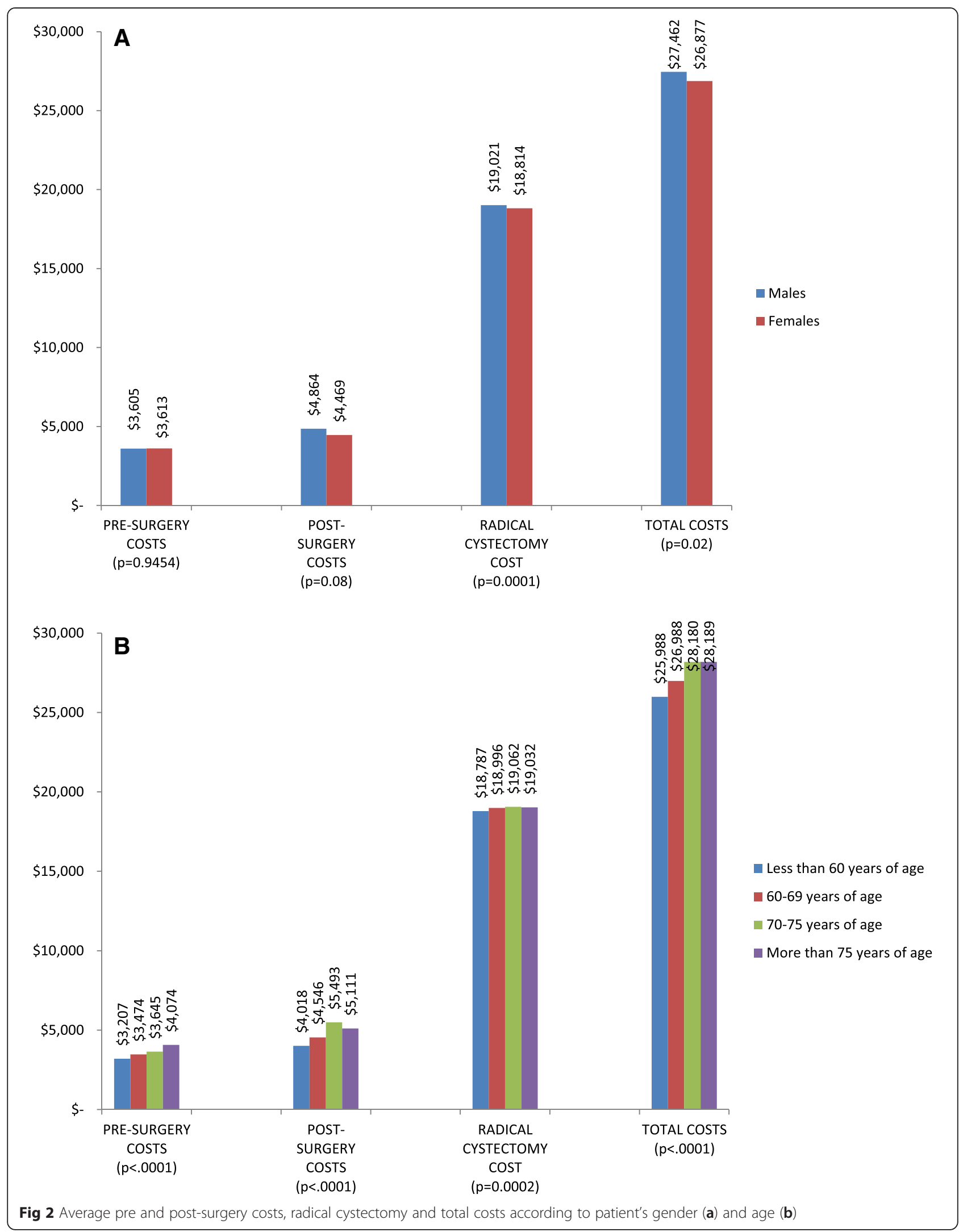




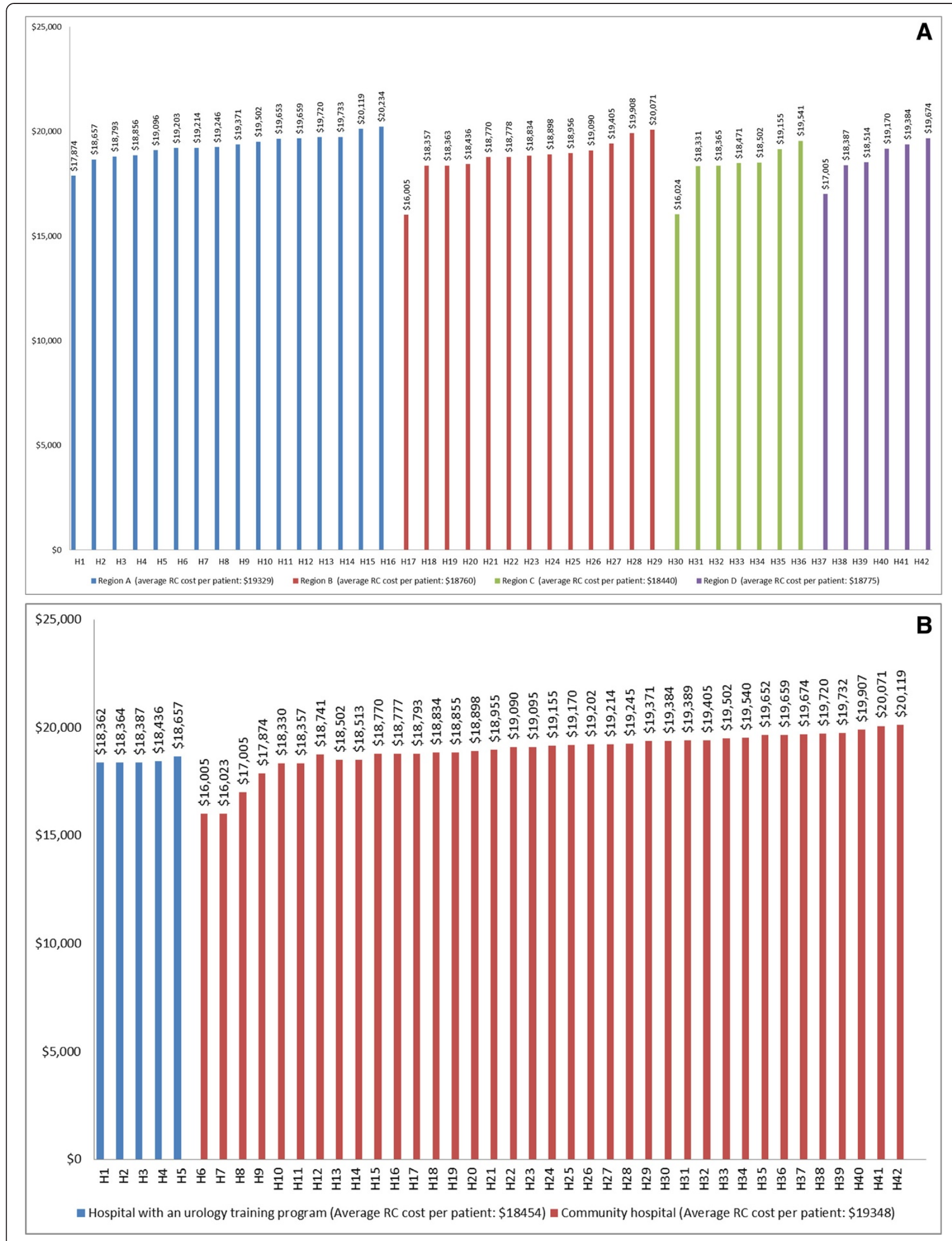

Fig 3 Variations for average RC costs among hospitals across the province (a), and according to the presence of a urology teaching program (b) 

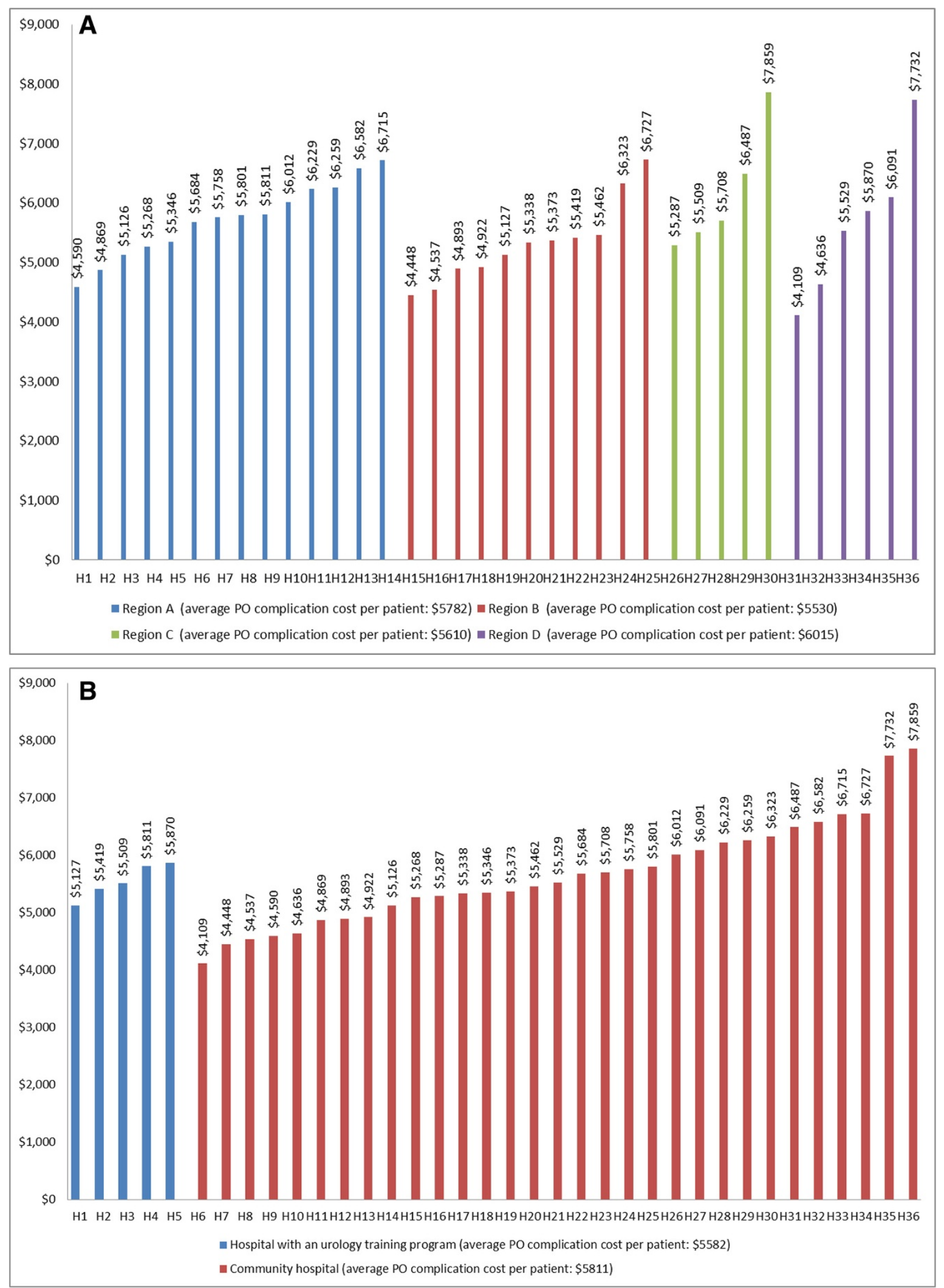

Fig. 4 Variations for average post-operative complications costs among hospitals across the province (a), and according to the presence of a urology teaching program (b) 
Table 4 Health-care services utilization and total costs associated with bladder cancer. (Time window: from four months before radical cystectomy up to 1 year post surgery; Costs in Canadian dollars)

\begin{tabular}{|c|c|c|c|}
\hline & $\begin{array}{l}\mathrm{N}(\% \text { of the } \\
\text { total study } \\
\text { population) }\end{array}$ & Total Units & $\begin{array}{l}\text { Total costs } \\
\text { (Canadian } \\
\text { dollars) } \\
\end{array}$ \\
\hline \multicolumn{4}{|l|}{ PRE-SURGERY COSTS $(n=2759)$} \\
\hline $\begin{array}{l}\text { Pre-urologist consultations } \\
\text { (all specialties confounded) }\end{array}$ & $2332(84.5 \%)$ & 9931 & 2040407 \\
\hline $\begin{array}{l}\text { Post-urologist consultations } \\
\text { (all specialties confounded) }\end{array}$ & 2155 (78.1\%) & 8853 & 1906147 \\
\hline Urologist consultations & 2731 (99 \%) & 10975 & 385244 \\
\hline Cystoscopies & 1896 (68.7 \%) & 2103 & 577135 \\
\hline TURBTs & 2058 (74.6 \%) & 2274 & 4340247 \\
\hline Imaging (physician fees) & 2532 (91.7 \%) & 5658 & 551684 \\
\hline \multicolumn{4}{|l|}{ RADICAL CYSTECTOMY COSTS } \\
\hline Radical cystectomy & $2759(100 \%)$ & 2759 & 52372057 \\
\hline \multicolumn{4}{|l|}{ POST-SURGERY COSTS } \\
\hline $\begin{array}{l}\text { Post-operative urologist } \\
\text { consultations }\end{array}$ & 2606 (94.5\%) & 22697 & 1073025 \\
\hline $\begin{array}{l}\text { Post-operative consultations } \\
\text { (all specialties confounded) }\end{array}$ & 2742 (99.4 \%) & 81562 & 5594774 \\
\hline $\begin{array}{l}\text { Post-operative medical } \\
\text { oncologist consultations }\end{array}$ & $809(29.3 \%)$ & 7728 & 406170 \\
\hline $\begin{array}{l}\text { Post-operative imaging } \\
\text { (physician fees) }\end{array}$ & 2535 (92.1\%) & 10716 & 945316 \\
\hline Post-operative complications & $811(29.4 \%)$ & 2839 & 4356127 \\
\hline
\end{tabular}

consultations, compared to the mean for the entire study period (Table 6). Stationarity analyses did not reveal any time trend for the number of RC performed during each month period, as well as for average pre-operative costs per month.

\section{Discussion}

Previous studies have shown that radical cystectomy accounts for the largest proportion of payments for bladder cancer care; these costs showing great variability depending on the country $[8,16]$. For example, average European RC reimbursement costs in US dollars, (including hospitalizations costs and medical fees) varies from 5684 \$ in the United Kingdom, 9697 \$ in France, 10932 \$ in Belgium and 15419 \$ in Germany [7]. The cost of radical cystectomy including lymphadenectomy and urinary diversion at an academic hospital center in the USA was calculated at 30000 \$ with most costs attributed to the operating room and hospital stay [8]. In our study, RC costs in Quebec lies between the estimates for Europe and North America and represents $69 \%$ of average costs of bladder cancer requiring RC from diagnosis to one year after surgery. This variation in surgery costs estimates across countries is probably attributable to differences in practices such as inpatient or outpatient care, duration of hospitalization, methods of calculating costs and billing, disease incidence, and the type of surgical procedure (open, laparoscopic, or robot-assisted) [17].

Our findings also showed variations in costs for $\mathrm{RC}$ within the provincial health-care system. Costs of surgery varied across patient gender, patient age group, and administrative region where $\mathrm{RC}$ was performed. Cost variations were also detected across individual hospitals, with the majority of facilities performing surgeries at a higher than the average cost. Although these disparities were relatively small, we detected a significant 1000 \$ greater average cost per patient between community hospitals compared to hospitals hosting a urology training program. Given that hospitalization and operation room costs were estimated with the provincial ministry of health's data and attributed equally to all surgical procedures in all hospitals in our cohort, we believe that this difference is caused by the greater amount of medical fees reimbursed to physicians in community hospitals. Indeed, we found that among community hospitals, surgeries are performed by an average of 2.9 surgeons (SD: 1.15), compared to 1.76 (SD: 0.9) among hospitals hosting a urology training program. This is likely explained by the fact that in academic centers the primary surgeon is often assisted by resident house staff that does not require reimbursement by the RAMQ, as opposed to community hospitals where 2 or more surgeons are involved, each billing the RAMQ. It has been reported that logistical difficulties inherent to the additional burden of excess travel time for patients and physicians and the potential marginalization of lowervolume hospitals may increase the indirect costs attributable to surgery in community hospitals [18]. Our results may be useful in identifying potential geographic disparities in the cost of $\mathrm{BC}$ cancer care.

Given that $\mathrm{BC}$ requires patients to undergo laboratory tests and invasive procedures for diagnosis, much of the costs during the management of the disease are attributed to cystoscopy and TURBT [19]. The frequent number of these procedures among bladder cancer patients results in significant cumulative costs [20]. Reimbursement for cystoscopy in the USA by Medicare is approximately $223 \$[8]$. Average costs of cystoscopy in our study (323 \$) were higher than some European countries with similar publically funded health system, such as Italy (76 \$), Germany (61 \$), France (51 \$), but considerably lower than UK (620 \$) [7]. On the other hand, average costs of TURBT in Quebec (2159 \$) showed to be similar to these countries (UK: 2154 \$; Germany: 1967 \$, France: 1124 \$, Italy: 2741 \$ and Belgium: 2201 \$) [7]. TURBT represents the first line of treatment for new tumors and accounts for a substantial portion of total bladder treatment costs [6]. In the 
Table 5 Costs associated with bladder cancer stratified by year of surgical procedure. (Time window: from four months before radical cystectomy up to 1 year post surgery; Costs in Canadian dollars)

\begin{tabular}{|c|c|c|c|c|c|c|c|c|c|}
\hline Year & $\begin{array}{l}\text { Number of RC } \\
\text { performed by year }\end{array}$ & $\begin{array}{l}\text { Average RC cost per } \\
\text { patient by year }\end{array}$ & $\begin{array}{l}\text { Total } R C \text { cost } \\
\text { per year }\end{array}$ & $\begin{array}{l}\text { Average pre-surgery costs } \\
\text { per patient by year }\end{array}$ & $\begin{array}{l}\text { Total pre-surgery } \\
\text { costs per year }\end{array}$ & $\begin{array}{l}\text { Average post-surgery } \\
\text { costs per patient by year }\end{array}$ & $\begin{array}{l}\text { Total post-surgery } \\
\text { costs by year }\end{array}$ & $\begin{array}{l}\text { Average total } B C \text { costs } \\
\text { per patient by year }\end{array}$ & $\begin{array}{l}\text { Total } B C \text { costs } \\
\text { by year }\end{array}$ \\
\hline 2000 & 268 & 19048 & 5104977 & 3436 & 921024 & 3908 & 1047425 & 26393 & 7073427 \\
\hline 2001 & 281 & 19246 & 5408320 & 3516 & 988186 & 4248 & 1193806 & 27011 & 7590313 \\
\hline 2002 & 265 & 19284 & 5110398 & 3296 & 870384 & 4475 & 1176988 & 27010 & 7157771 \\
\hline 2003 & 260 & 19214 & 4995825 & 3334 & 867014 & 4752 & 1230848 & 27283 & 7093688 \\
\hline 2004 & 289 & 19207 & 5551009 & 3725 & 1076586 & 5243 & 1504842 & 28139 & 8132438 \\
\hline 2005 & 297 & 19133 & 5682666 & 3743 & 1108099 & 5458 & 1621090 & 28322 & 8411856 \\
\hline 2006 & 282 & 18833 & 5311004 & 3708 & 1045657 & 5938 & 1674592 & 28479 & 8031253 \\
\hline 2007 & 282 & 18582 & 5240391 & 3693 & 1041576 & 5600 & 1573614 & 27856 & 7855582 \\
\hline 2008 & 278 & 18645 & 5183322 & 3609 & 1003438 & 5302 & 1463482 & 27518 & 7650243 \\
\hline 2009 & 257 & 18615 & 4784141 & 3717 & 955341 & 3298 & 827833 & 25553 & 6567317 \\
\hline Total & 2759 & 18979 & 52372057 & 3762 & 9877310 & 4770 & 13314525 & 27388 & 75563893 \\
\hline
\end{tabular}




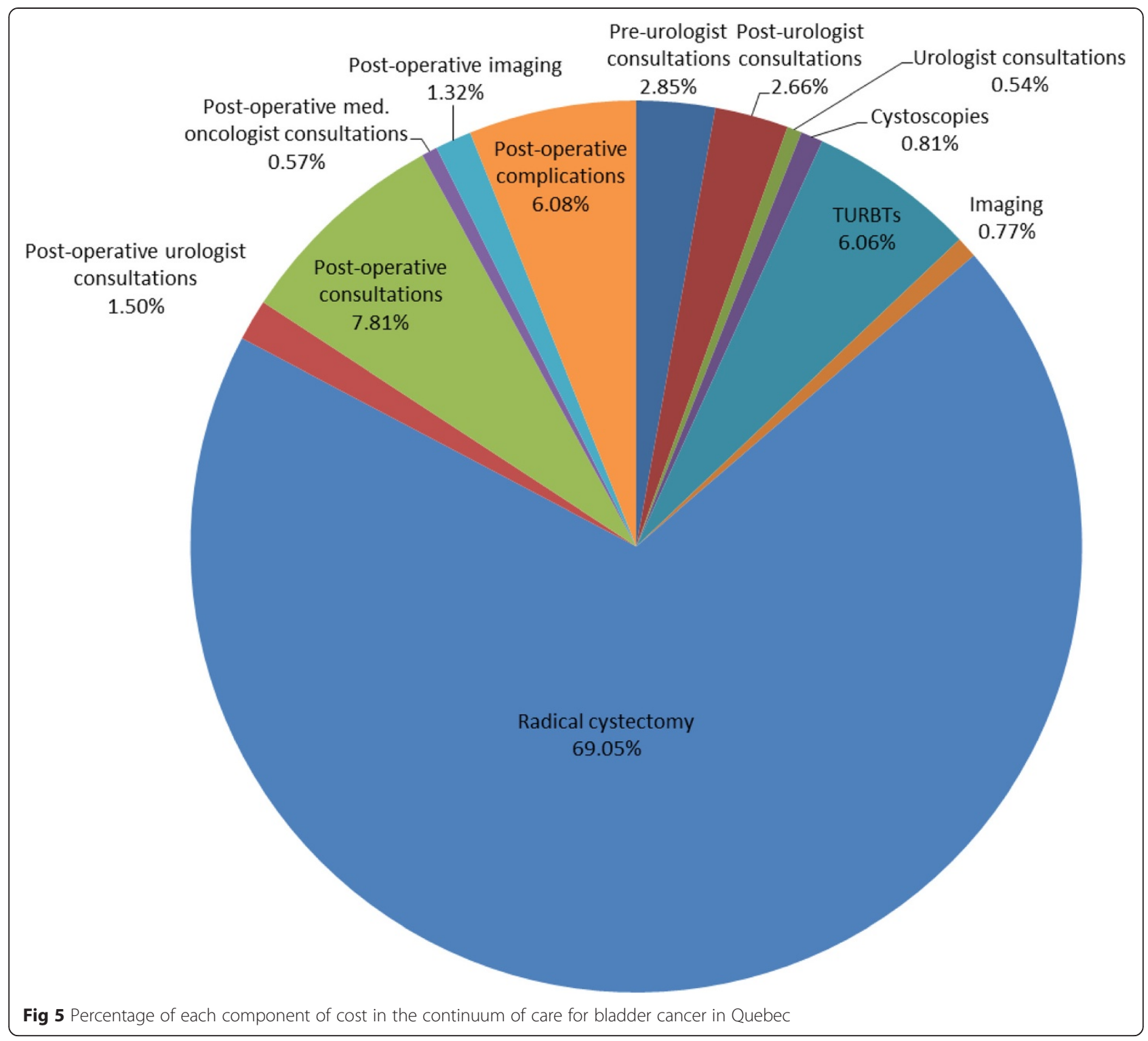

USA, after accounting for costs of anesthesia and the operating room, these costs were estimated to be higher than $2900 \$[21]$. Costs at an academic US medical center ranged from 3000 \$ to 6000 \$ depending on patients average hospitalization duration [8]. In this study, the mean length of stay was 2 days which contributed to this variation of TURBT costs. In some centers, patients spend an average of 4 days in the hospital after a TURBT. One day surgery is common in Quebec [13, 14].

Surgery for bladder cancer carries a high risk for perioperative and post-operative complications with rates varying from $20 \%$ to $60 \%$ [22, 23]. A recent study conducted by our group estimated that in Quebec postoperative complications occur in $30 \%$ of RC cases [12].
Complications of radical cystectomy prolong the patient's length of hospital stay and significantly increase the total bladder cancer costs [24]. Estimated costs of complications vary greatly across different studies according to definitions and categorization of postoperative complications, and consequently duration of hospital stay. One of the highest costs attributable to an adverse event after cystectomy was shown for sepsis in the USA [25]. In this study, length of stay for patients with septicemia was estimated at 29 days compared with 10 days for controls. Hospital charges for bacterial infections was 107724 \$. Average costs for selected postoperative complications [12] in our study was estimated at $5703 \$$, which is lower than other average estimates in the literature [8]. A great variation in costs was observed 

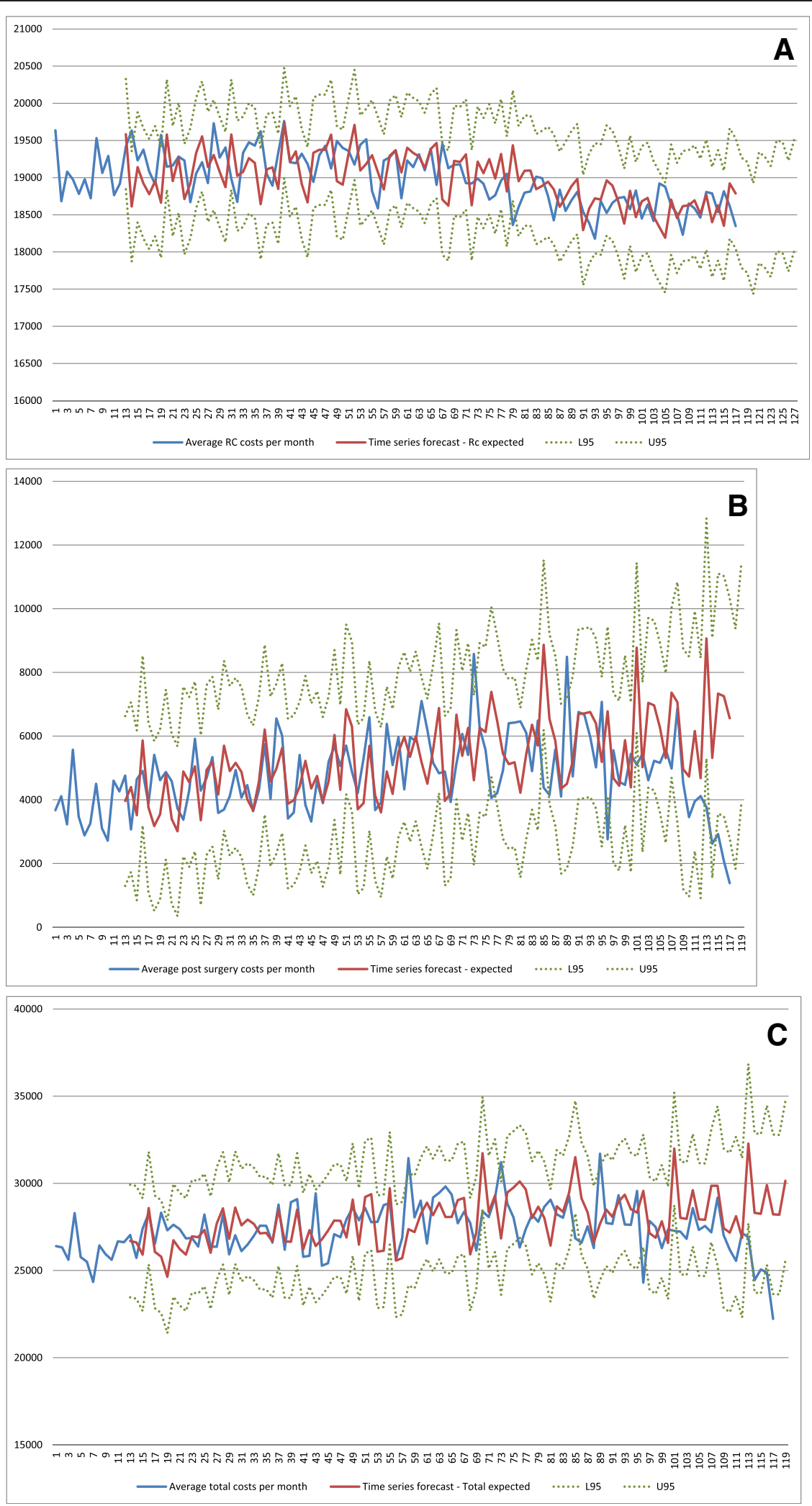

Fig 6 Time series trends in cost per patient (y axis) over time (x axis): (a) Average RC costs; (b) Average post-operative costs; (c) Average total costs * 
Table 6 Average costs for consultations in September 2009, compared to average forecasted values from ARIMA $(1,1,0)$ model, and average costs for the study period

\begin{tabular}{|c|c|c|c|c|c|}
\hline & $\begin{array}{l}\text { Mean and standard deviation } \\
\text { (SD) of costs for September } 2009 \\
\text { (Canadian dollars) }\end{array}$ & $\begin{array}{l}\text { Median and range of } \\
\text { costs for September } 2009 \\
\text { (Canadian dollars) }\end{array}$ & $\begin{array}{l}\text { Mean and standard deviation } \\
\text { (SD) of costs over all study } \\
\text { period (Canadian dollars) }\end{array}$ & $\begin{array}{l}\text { Median and range of } \\
\text { costs over all study period } \\
\text { (Canadian dollars) }\end{array}$ & $\begin{array}{l}\text { Predicted costs values } \\
\text { for September } 2009 \text { - } \\
\text { ARIMA }(1,1,0)\end{array}$ \\
\hline $\begin{array}{l}\text { Pre-urologist consultations } \\
\text { (all specialties confounded) }\end{array}$ & Mean: 667 (825) & Median: 362 (20-3156) & Mean: 1006 (1299) & Median: 450 (10-7834) & $*$ \\
\hline $\begin{array}{l}\text { Post-urologist consultations } \\
\text { (all specialties confounded) }\end{array}$ & Mean: 712 (569) & Median: 428 (104-3511) & Mean: 935 (1038) & Median: 523 (6.2-6000) & * \\
\hline Urologist consultations & Mean: 127 (85) & Median: 129 (16.9-245) & Mean: 162 (80) & Median: 140 (17-1959) & * \\
\hline $\begin{array}{l}\text { Post-operative consultations } \\
\text { (all specialties confounded) }\end{array}$ & Mean: 453 (345) & Median: 261 (64-1724) & Mean: 2232 (2275) & Median: 1464 (17-27057) & * \\
\hline Post-operative imaging & Mean: 139 (326) & Median: 90 (31.6-496) & Mean: 395 (307) & Median: 311 (12.3-2845) & * \\
\hline Post-operative costs & Mean: 1384 (589) & Median: 278 (57.8-11615) & Mean: 4770 (5220) & Median: 2759 (33.8-42000) & $\begin{array}{l}6559 \\
\text { (95 \% Cl: 1827-9366) }\end{array}$ \\
\hline Total costs & Mean: 22223 (19560) & Median: 21075 (17341-33249) & Mean: 27326 (18652) & Median: 25928 (17222-62000) & 28224 (95 \% Cl: 23654-32794) \\
\hline
\end{tabular}


between hospitals in Quebec with a range of 4109 \$ 7732 \$. Similar to what was detected for RC average costs, community hospitals showed higher average postoperative complication costs per patients, compared to academic hospitals. More studies investigating predictors of higher costs and the impact of cost disparities and its relation to outcome and survival are needed.

Average total costs per patient in Quebec was found to be lower than the Canadian province of Ontario (27 388 \$ in Quebec versus 33759 \$ in Ontario) [26]. Although we cannot establish causal relations between medical costs and patient outcomes based on such ecological data, it is noteworthy that 5-year overall survival after RC in Quebec is $46 \%$, while the rate is $35 \%$ in Ontario [18].

During the study period, total costs of bladder cancer requiring $\mathrm{RC}$ from diagnosis up to one year of follow up were estimated at more than 70 million dollars, with more than $70 \%$ of this total expenditure attributed to health care associated to surgery. Total costs of surgery and post-operative complications were estimated at 50 million dollars and 4 million dollars, respectively. Total costs in our cohort represent a small fraction of what was estimated in the USA for 2010 (3.98 billion dollars, for all cases confounded) [27]. Reasons for the rising cost of bladder cancer in the USA are attributable to the fact that most patients in the US are part of the Medicare Program [1]. In addition, Medicare reviewed its reimbursement fees for office-based endoscopic procedures in 2005, which led to an increased number of bladder lesions detected and a higher total number of bladder cancer-related procedures being performed [28]. Total costs estimates in the United Kingdom included estimates of indirect costs from loss of earnings and reached 125.2 million in 2010 [29]. Cost of the annual medical care was estimated to be about 1 million dollars in Sweden [19] and 27 million dollars in South Korea [30]. These remarkable variations are due to differences in both disease incidence and costs of per patient treatment in each national health system. Analyses of specific explanatory differences in clinical structure or the availability of resources have not been extensively investigated [1]. A noteworthy result of our study was a decreasing trend in the average post-operative costs and total costs caused by a lower average cost for consultations observed in the year 2009.

To our knowledge, this is the first study to describe costs attributed to the number of pre and posturologist consultations to general practitioners and other specialists, as well as the costs associated to urologist consultation during the pre and post-operative period. Given the paucity of detailed descriptive studies on the health economics of BC in Canada [26], our results provide some evidence-based data of interest to health care providers and policy-makers to better understand the relationship between resourceutilization and costs associated with the disease, and to improve the efficiency and outcomes.

This study had some significant limitations inherent to the use of administrative databases. We were unable to measure some factors that can play an important role on costs of $B C$ requiring $R C$, such as grade, stage and severity of the tumor. Data on comorbidity and patient functional status are also lacking. More importantly, since we did not know the actual hospitalization period for each patient undergoing RC, we could not be more precise in attributing costs to $\mathrm{RC}$ and postoperative complications. The actual variance of health services costs is hence, mainly due to the overall differences in billing codes for physicians' payments. This information would be very important in order to compare costs and efficiencies between administrative regions, individual hospitals, and surgeons. The imputation of some economic component for medical services may have caused some degree of information bias in the calculation of average costs per patient. Nevertheless, if information bias is present, it is certainly non-differential, which not undermine internal validity of our findings. Given that we do not have data on some medical services such as prescriptions filled by patients, we could not compare our findings with an external cohort of patients that would serve as control group for estimation and comparison of attributable and net costs. Moreover, considering the intrinsic discrepancies in the management of $\mathrm{BC}$ across different health care systems, we are not convinced that comparing of our findings in the province of Quebec with a different "control cohort" would decrease the possibility of information bias.

Also, our study did not account for the burden of indirect costs in our analyses, for which we acknowledge that these costs in the form of patients' and caregivers' time, as well as reduced physical and social functioning contribute to the overall burden of bladder cancer on society. On the other hand, the fact that the RAMQ is single-payer and public funded system with universal healthcare coverage allows the collection of prospective information for a large sample size, which increases external validity of our findings. The linkage between the two databases was done using a unique patient identifier, which permitted a very reliable correspondence of medical services data [31].

\section{Conclusion}

Costs of RC surgery, TURBT, medical consultations, and post-operative complications were the most important economic components of total bladder cancer cost per patient requiring radical cystectomy in Quebec. Significant variations in costs were detected 
between academic and community hospital, as well as between geo-administrative regions across the province. More studies are needed to evaluate predictors of costs and the impact of bladder cancer expenditures on patient's clinic outcome and survival.

\section{Abbreviations}

BC: bladder cancer; RC: radical cystectomy; TURBT: transurethral resection of the bladder tumor; RAMQ: Régie de l'assurance maladie du Québec; ISQ: Institut de la statistique du Québec; CAl: Comission de l'acces a l'information; MSSS: Ministere de la Sante et des Services Sociaux; ICD-9: International classification of diseases - 9th edition; ARIMA: autoregressive integrated moving average.

\section{Competing interests}

The authors have no conflicts of interest to declare.

\section{Authors' contributions}

Each author has participated actively and sufficiently in this study. FS conducted the study, performed the analyses, and led the writing of the manuscript. AZ, WK and $A D$ helped to interpret the results, and revised the manuscript for important intellectual content. AA conceived and supervised the study. All authors read and approved the final manuscript.

\section{Acknowledgements}

This study was supported by the Canadian Institutes of Health Research [funding reference number 127596] in partnership with Bladder Cancer Canada, and the McGill Integrated Cancer Research Training Program (MICRTP).

\section{Author details}

${ }^{1}$ Division of Cancer Epidemiology, Department of Oncology, McGill University, 546 Pine Avenue West, Montreal, QC, Canada. ${ }^{2}$ Division of Urology, Department of Urology, McGill University Health Centre, 1650 Cedar Avenue, Montreal, QC, Canada.

\section{Received: 9 January 2015 Accepted: 24 July 2015}

Published online: 05 August 2015

\section{References}

1. Yeung C, Dinh T, Lee J. The Health Economics of Bladder Cancer: An Updated Review of the Published Literature. PharmacoEconomics. 2014.

2. Kaplan AL, Litwin MS, Chamie K. The future of bladder cancer care in the USA. Nature reviews Urology. 2014;11(1):59-62.

3. Raghavan D, Quinn D, Skinner DG, Stein JP. Surgery and adjunctive chemotherapy for invasive bladder cancer. Surgical oncology. 2002;11(1-2):55-63.

4. Statistics CCSsACoC. Canadian Cancer Statistics 2014. Toronto, ON: Canadian Cancer Society, 2014 2014. Report No.

5. Siegel R, Ma J, Zou Z, Jemal A. Cancer statistics, 2014. CA: a cancer journal for clinicians. 2014;64(1):9-29.

6. Yafi FA, Aprikian AG, Fradet Y, Chin JL, Izawa J, Rendon R, et al. Surveillance guidelines based on recurrence patterns after radical cystectomy for bladder cancer: the Canadian Bladder Cancer Network experience. BJU international. 2012;110(9):1317-23.

7. Sievert KD, Amend B, Nagele U, Schilling D, Bedke J, Horstmann M, et al. Economic aspects of bladder cancer: what are the benefits and costs? World journal of urology. 2009;27(3):295-300.

8. Svatek RS, Hollenbeck BK, Holmang S, Lee R, Kim SP, Stenzl A, et al. The Economics of Bladder Cancer: Costs and Considerations of Caring for This Disease. European urology. 2014.

9. Wollin T, Laroche B, Psooy K. Canadian guidelines for the management of asymptomatic microscopic hematuria in adults. Canadian Urological Association journal = Journal de l'Association des urologues du Canada. 2009;3(1):77-80.

10. (RAMQ) RdlAMdQ. Manuel des Medecins Specialistes. Quebec: RAMQ; 2012.

11. RdlAMd Q. Manuel des Medecins Omnipraticiens. Regie de l'Assurance Maladie du Quebec: Quebec; 2012.
12. Zakaria AS, Santos F, Dragomir A, Tanguay S, Kassouf W, Aprikian AG Postoperative mortality and complications after radical cystectomy for bladder cancer in Quebec: A population-based analysis during the years 2000-2009. Canadian Urological Association journal = Journal de I'Association des urologues du Canada. 2014;8(7-8):259-67.

13. Information ClfH. The Cost of Acute Care Hospital Stays by Medical Condition in Canada. Canadian Institute for Health Information: Ottawa; 2008.

14. Sociaux MdlSedS. Banque de Donnees APR-DRG 2010-2011 et Contour Financier de Sante Physique (Ministry of Health and Social Services, Database APR-DRG 2010-2011 and financial outline of physical Health). Quebec2014 [cited 2014]. Available from: forma.msss.gouv.qc.ca/ Details.aspx?ld50LgRnU5HvPw.

15. I'information MQ-Ddlgid. Atlas de la Santé et des Services sociaux du Québec Quebec2014 [cited 2014 Oct, 27th, 2014]. Available from: http:// www.msss.gouv.qc.ca/statistiques/atlas/atlas/index.php?id_carte=86.

16. Riley GF, Potosky AL, Lubitz JD, Kessler LG. Medicare payments from diagnosis to death for elderly cancer patients by stage at diagnosis. Medical care. 1995;33(8):828-41.

17. Bryan RT, Kirby R, O'Brien T, Mostafid H. So Much Cost, Such Little Progress. European urology. 2014.

18. Kulkarni GS, Urbach DR, Austin PC, Fleshner NE, Laupacis A. Higher surgeon and hospital volume improves long-term survival after radical cystectomy. Cancer. 2013;119(19):3546-54

19. Hedelin H, Holmang S, Wiman L. The cost of bladder tumour treatment and follow-up. Scandinavian journal of urology and nephrology. 2002;36(5):344-7.

20. Botteman MF, Pashos CL, Redaelli A, Laskin B, Hauser R. The health economics of bladder cancer: a comprehensive review of the published literature. PharmacoEconomics. 2003;21(18):1315-30.

21. Green DA, Rink M, Cha EK, Xylinas E, Chughtai B, Scherr DS, et al. Cost-effective treatment of low-risk carcinoma not invading bladder muscle. BJU international. 2013;111(3 Pt B):E78-84.

22. Shabsigh A, Korets R, Vora KC, Brooks CM, Cronin AM, Savage C, et al. Defining early morbidity of radical cystectomy for patients with bladder cancer using a standardized reporting methodology. European urology. 2009;55(1):164-74.

23. Meller AE, Nesrallah $\amalg$, Dall'Oglio MF, Srougi M. Complications in radical cystectomy performed at a teaching hospital. International braz j urol : official journal of the Brazilian Society of Urology. 2002;28(6):522-5.

24. Kim SP, Shah ND, Karnes RJ, Weight CJ, Frank I, Moriarty JP, et al. The implications of hospital acquired adverse events on mortality, length of stay and costs for patients undergoing radical cystectomy for bladder cancer. The Journal of urology. 2012;187(6):2011-7.

25. Davies BJ, Allareddy V, Konety BR. Effect of postcystectomy infectious complications on cost, length of stay, and mortality. Urology. 2009;73(3):598-602.

26. de Oliveira C, Bremner KE, Pataky R, Gunraj N, Chan K, Peacock S, et al. Understanding the costs of cancer care before and after diagnosis for the 21 most common cancers in Ontario: a population-based descriptive study. CMAJ open. 2013;1(1):E1-8.

27. Mariotto AB, Yabroff KR, Shao Y, Feuer EJ, Brown ML. Projections of the cost of cancer care in the United States: 2010-2020. Journal of the National Cancer Institute. 2011;103(2):117-28.

28. Penson DF. Medicare reimbursement changes for bladder biopsies: a cautionary tale of unintended consequences. Cancer. 2010;116(5):1153-4.

29. Sangar VK, Ragavan N, Matanhelia SS, Watson MW, Blades RA. The economic consequences of prostate and bladder cancer in the UK. BJU international. 2005;95(1):59-63.

30. Kim SG, Hahm MI, Choi KS, Seung NY, Shin HR, Park EC. The economic burden of cancer in Korea in 2002. European journal of cancer care. 2008;17(2):136-44.

31. Santos F, Dragomir A, Kassouf W, Franco EL, Aprikian A. Predictors of preoperative delays before radical cystectomy for bladder cancer in Quebec, Canada: a population-based study. BJU international. 2015;115(3):389-96. 